\title{
Public Transportation on the Era of Autonomous Vehicles: Exploring Different Scenarios
}

\author{
Kareem Othman ${ }^{1,2 *}$ \\ ${ }^{1}$ Civil engineering department, University of Toronto, Toronto, Canada \\ ${ }^{2}$ Public works department, Faculty of engineering, Cairo University, Giza, Egypt
}

Submission: October 02, 2020; Published: October 19, 2020

*Corresponding author: Kareem Othman, Civil engineering department, University of Toronto, Toronto, Canada

\begin{abstract}
Research on vehicle automation has launched many years ago. Over the last decade, autonomous vehicles (AVs) have witnessed tremendous improvement because of the significant effort dedicated to AVs from both research and industry. Despite the enthusiastic speculation of AVs, little is known about the influence of vehicle automation on the public transit service. Thus, the main goal of this paper is to investigate and explore the implications of vehicle automation on the shape of public transit. In this paper three scenarios of AVs adoption are explored: autonomous vehicles are used for the entire trip (AV as a competitor to the public transportation), integrated AVs with the current public transit system (AVs are used to solve the first mile last mile problem to increase the attractive ness of the transit service), and fully autonomous buses. Finally, results show that a combination between scenario two and three is the recommended scenario in order to derive the optimal benefits of the automation technology.
\end{abstract}

Keywords: Autonomous vehicles; Autonomous buses; Public transportation

\section{Introduction}

It is commonly known that mobility is affected by technology. Trough history, technology and innovation have had a significant influence on peoples' life such as mode of transportation, residence location, and thus their lifestyle. However, the integration of these new technologies with the existing transportation service might be a harsh process that might force the old technology to diminish. Nowadays, as most of the world's population are using smartphones, technology appears to be the most important factor that influence people's mobility.

Over the past few years, extensive number of studies have been dedicated to vehicle automation. Additionally, AVs are already in the market and have been tested for few years now. Thus, many researchers study the chances, implications, benefits, drawbacks, public acceptance, and challenges of autonomous vehicles. AV is poised to be one of the most disruptive technologies in the near future. It is expected that the adaption and commercialization of AVs will have extensive impacts in the shape of our lives. Previous studies show that AVs will have a significant influence on the safety level, congestions, land use, level of emissions and energy consumption. Definitely, public transportations (PT) will be affected by the introduction of AVs.
Studies on AVs indicate that AVs promises many benefits such as the increase in the level of safety, the reduction in the required fleet size, and the increase in value of land use. With the anticipated benefits of AVs, it is expected that AVs have the potential to adversely impact the ridership, and viability of the public transportation service [1-3]. This impact can be considered as threat to public transit and social equity. However, limited number of studied provide insights on the relationship between AVs and public transportation service and AVs are mostly considered as a competitor to the public transit service $[4,5]$. Additionally, the level of mobility increases in all cities across the world. This increase is associated with increase in the levels of congestion, noise, greenhouse gas emissions, and traffic accidents. Thus, one of the most important strategies to meet urban transportation challenges and its unintended outcomes is to facilitate a shift from personal car use into public transportation use. Thus, the main goal of this study is to investigate the impact of AVs technology on the public transportation service by instigating different scenarios and provide some insights and guidelines for the future on how to integrate AVs with transit service in order to derive the optimal benefits of the new technology. 


\section{Civil Engineering Research Journal}

Scenario 1: Autonomous vehicles as a competitor to public transportation (the entire trip is made by AVs)

Most of the studies in the literature focus on this scenario and assumes that all or private car trips will be made by AVs or shared AVs. Table 1 summarizes some of these studies and show their assumptions and results:

Table 1: Summary of the methodology and results of studies that simulate AVs as a private or shared mode.

\begin{tabular}{|c|c|c|c|}
\hline Study & Methodology & Assumptions & Results \\
\hline Burns L. et al. [12] & $\begin{array}{c}\text { Queuing, network, and simulation } \\
\text { models for three cities in the US: } \\
\text { Ann Arbor, Michigan; Babcock } \\
\text { Ranch, Florida; Manhattan, New } \\
\text { York }\end{array}$ & $\begin{array}{c}\text { Ann Arbor, Michigan: } \\
\text { Replacing the private } \\
\text { cars with fleets of shared } \\
\text { autonomous vehicles (AVs) } \\
\text { for trips less than } 70 \text { miles. } \\
\text { Manhattan: Replacing the } \\
\text { yellow taxicab with fleets of } \\
\text { shared autonomous vehicles (AVs) } \\
\text { The service area is } 10 \text { miles } \\
\text { by } 10 \text { miles and the city is divided } \\
\text { to } 0.25 \text { mile by } 0.25 \text { mile zones } \\
\text { (1600 zones). }\end{array}$ & $\begin{array}{l}\text { Results show significant increase } \\
\text { in the VKT }(75 \%) \text { and significant } \\
\text { reduction in the trip cost. }\end{array}$ \\
\hline $\begin{array}{c}\text { Kockelman, Fagnant } \\
{[13]}\end{array}$ & Agent-based simulation model. & $\begin{array}{c}\text { The service area is } 10 \text { miles by } \\
10 \text { miles and the city is divided to } \\
0.25 \text { mile by } 0.25 \text { mile zones ( } 1600 \\
\text { zones). }\end{array}$ & $\begin{array}{l}11 \% \text { increase in the VKT due to } \\
\text { AVs relocation and relocation to } \\
\text { cheap parking areas during low } \\
\text { demand. }\end{array}$ \\
\hline $\begin{array}{l}\text { International transport } \\
\text { forum [14] }\end{array}$ & $\begin{array}{l}\text { Simulation model for Lisbon, } \\
\text { Portugal }\end{array}$ & $\begin{array}{l}\text { All trips less than } 1 \text { kilometer } \\
\text { are taken on foot or by bicycle. } \\
\text { There are three categories of } \\
\text { AV: two, five and eight passengers. } \\
\text { Passenger waiting } \\
\text { time is } 5 \text { min or lower. } \\
\text { Two scenarios were } \\
\text { investigated: } 50 \% \text { or } 100 \% \text { of the } \\
\text { trips will be made by AVs. }\end{array}$ & $\begin{array}{c}\text { Results show that AVs } \\
\text { would increase the VKT } \\
\text { significantly up to } 89 \% \text { with } \\
100 \% \text { AVs penetration rate. } \\
50 \% \mathrm{AV} \text { (at the peak) increases } \\
\text { the traffic which increases the } \\
\text { congestion level. }\end{array}$ \\
\hline $\begin{array}{c}\text { Bischoff, Maciejewski } \\
{[11]}\end{array}$ & $\begin{array}{l}\text { microscopic simulation } \\
\text { "MATSim" for Berlin, Germany }\end{array}$ & AVs will replace private car trips. & $\begin{array}{l}\text { Results show significant increase } \\
\text { in the total travel time }(17 \%) \\
\text { because of the empty trips. }\end{array}$ \\
\hline $\begin{array}{l}\text { Zhang, Guhathakurta } \\
{[17]}\end{array}$ & $\begin{array}{l}\text { Investigate the impact of three } \\
\text { different parking scenarios } \\
\text { for City of Atlanta, USA on the } \\
\text { behavior of AVs using simulation } \\
\text { models: Free parking, entrance- } \\
\text { based charge, and time based } \\
\text { charged }\end{array}$ & $\begin{array}{l}\text { When the AV becomes } \\
\text { idle it looks for the parking } \\
\text { with the lowest total cost. } \\
\text {. } 5 \% \text { of residents would } \\
\text { use the AV instead their cars. } \\
\cdot \quad \text { This study assumes that } \\
\text { the parking attraction depends } \\
\text { only on the total parking cost. } \\
\text { It assumes that AVs try to } \\
\text { minimize its total cost all the time. } \\
\cdot \quad \text { AVs can be shared if they } \\
\text { satisfy a predefined criterion. }\end{array}$ & $\begin{array}{l}\text { Results show that } \\
\text { the parking strategy has a } \\
\text { significant influence in the VKT. } \\
\cdot \quad \text { VKT is } 5 \% \text { higher for } \\
\text { the entrance-based charging } \\
\text { scenario and } 14 \% \text { higher for the } \\
\text { time-based scenario. }\end{array}$ \\
\hline $\begin{array}{c}\text { Hörl, Erath, Axhausen } \\
\text { [6] }\end{array}$ & $\begin{array}{c}\text { Activity based trafficc simulation } \\
\text { framework MATSim for City of } \\
\text { Sioux Falls, U.S. }\end{array}$ & $\begin{array}{l}\text { At the beginning of } \\
\text { the day, AVs are randomly } \\
\text { distributed according to } \\
\text { the population density. } \\
\text {. Mode choice is based on a } \\
\text { set of behavioral parameters that } \\
\text { are used in another study on the } \\
\text { impact of the AVs on the mode } \\
\text { choice in the U.S by Kockelman, } \\
\text { Chen [4]. }\end{array}$ & $\begin{array}{l}\text { AVs are attractive to users } \\
\text { because of different reasons: } \\
\text { for private cars users, AVs } \\
\text { are much cheaper, while for } \\
\text { public transport users, AVs } \\
\text { reduce the waiting time and } \\
\text { avoid the walking distance } \\
\text { AVs increase the VKT which } \\
\text { has negative impact on the } \\
\text { environment which underlines } \\
\text { the significance of intelligent } \\
\text { policymaking regarding the use } \\
\text { of the AVs. }\end{array}$ \\
\hline
\end{tabular}




\begin{tabular}{|c|c|c|c|}
\hline $\begin{array}{l}\text { Moreno, Michalski, } \\
\text { Llorca, Moeckel [16] }\end{array}$ & $\begin{array}{l}\text { 1- } \quad \text { Traffic simulation model } \\
\text { using MATSim for greater Munich } \\
\text { metropolitan area to estimate the } \\
\text { impact of SAVs on the trip } \\
\text { duration and VKT. } \\
\text { 2- } \quad \text { Stated Preference Online } \\
\text { and on street Survey. }\end{array}$ & $\begin{array}{c}\text { Transportation mode } \\
\text { (Walking, Bicycle, Car or } \\
\text { transit) was selected based } \\
\text { on the travelling distance. } \\
\text { AVs users' choice of private or } \\
\text { shared rides was predicted using } \\
\text { the results of the stated preference } \\
\text { survey. }\end{array}$ & $\begin{array}{l}\text { Results show that in all scenarios } \\
\text { (different fleet sizes), AVs would } \\
\text { increase the VMT because of the } \\
\text { empty trips. }\end{array}$ \\
\hline Zhang W et al [18] & $\begin{array}{l}\text { Simulation model for the Atlanta } \\
\text { Metropolitan Area, U.S }\end{array}$ & $\begin{array}{l}\text { No change in the travel } \\
\text { behavior. } \\
\text { Vehicles are shared within the } \\
\text { same household members. } \\
\cdot \quad \text { AVs represent } 100 \% \text { of } \\
\text { the traffic flow. } \\
\text { Household features that are } \\
\text { correlated with the house } \\
\text { reduction were based on Atlanta } \\
\text { Travel Survey (2011). }\end{array}$ & $\begin{array}{l}\text { VKT for the households } \\
\text { would increase by } 59.5 \% \\
\text { compared with the current case. } \\
\cdot \quad \text { On average, households } \\
\text { will produce } 29.8 \text { miles more per } \\
\text { day per } \\
\text { Overall increase in the VKT was } \\
13.3 \% \text { reduced vehicle. }\end{array}$ \\
\hline Kloostra, Roorda [5] & $\begin{array}{c}\text { Simulation model using Emme } \\
4 \text { for the Greater Toronto Area } \\
\text { (GTA), Canada }\end{array}$ & $\begin{array}{l}\text { AV are used for personal } \\
\text { trips; no trip sharing. } \\
\text { Trip distribution data } \\
\text { are based on the transportation } \\
\text { tomorrow survey (2011) on the } \\
\text { GTA. }\end{array}$ & $\begin{array}{l}\text { The VMT increases with the } \\
\text { increase in the AVs penetration }\end{array}$ \\
\hline
\end{tabular}

As shown in Table 1, AVs will increase the VKT even if it was used as shared mode and replace the private car trips, which in turn means increase in the emissions, and congestion. Additionally, as shown in the previous studies AVs have the potential to reduce the trip cost significantly. Thus, AVs will be attractive to users because of different reasons: for private cars users, AVs are much cheaper, while for public transport users, AVs reduce the waiting time and avoid the walking distance [6]. Additionally, this reduction in the waiting time and trip cost might attract people to make additional trips or make longer trips, which again increase the VKT and worsen our lives.

\section{Scenario 2: Autonomous vehicles integrated with the} public transit service

This scenario is based on the assumption that AVs will be used as a first mile last mile solution to the support the existing transit system. In this case, it is assumed the AVs are owned and operated by transit agencies or transit operators. AVs are as a first mile last mile solution can increase the reliance and attractiveness of PT system. However, studies on integrated $\mathrm{AV}+\mathrm{PT}$ solutions have just begun recently $[7,8]$. In these studies, AVs were used as an ondemand service that allow passengers to travel from their location to their preferred transit point. In these studies, AVs were used as an on-demand service that allow passengers to travel from their location to their preferred transit point.

For example, Wen J et al. [7] used agent-based simulation model to study the opportunities of using shared AVs to support public transit as a first mile- last mile solution. Additionally, the impact of sharing of AVs was studies as three scenarios were considered: AV operator limits the capacity to 1 (non-sharing), sharing of 2 or 3 or 4 are investigated. Wen J et al. [7] built their study based on the following assumptions:

a. As AVs are used to support the transit system, passengers share their vehicles by default.

b. Service pricing is based on a cost based fare structure that include three main costs: based fare to discourage people of making short trips that can be made by other modes, per unit distance, and per unit time fare similar to the dynamic pricing.

c. AVs are assigned dynamically to satisfy constraints such as maximum waiting time and detour time with the objective of minimizing costs in terms of total travel times for all travelers.

d. AVs with a maximum capacity of 4 passengers is considered.

Results show that:

e. The total VKT increase with the increase in the fleet size which in turn means higher operating costs. This increase is due to the idle trips because of the rebalancing strategy to provide better service. Thus, the fleet sizing problem is a trade-off between the benefits to the travelers and the cost to the operators.

f. Sharing has a significant impact on the system performance. Results show that the required AVs can be reduced by more than half when a maximum of 4 passengers can be shared.

Thus, in this scenario, VKT increase with the increase in the fleet size. However, as in this scenario the required fleet size is way smaller than the required fleet size to serve the entire trips in scenario, the increase in the VKT in scenario 2 is much smaller than the increase in the VKT in scenario 1 . Thus, it can be concluded that this scenario is much better in our lives. 


\section{Civil Engineering Research Journal}

Scenario 3: Application of vehicle automation in public transportation (Adaption of Autonomous buses)

Research on automation of buses is rare and most of these studies are published in 2020. However, there are many benefits of using autonomous buses as follows:

a. On the era of autonomous buses, it is anticipated that passengers could expect to receive accurate information about their trips.

b. Vehicle automation will exclude the influence of driver (driving style, acceleration or deceleration, good or bad driver) on the bus performance.

c. Additionally, autonomous buses will not rely of drivers which means elimination of the wage costs of bus drivers.

d. Reduction or elimination of the fuel costs because of the expectations that autonomous vehicles will use electric engines.

Additionally, vehicles are the most expensive component on the transit system. However, vehicles and drivers are connected to each other because the vehicle remain idle in case of driver's break time which reduce the vehicle utilization. Thus, the efficiency of the current system is usually between 60 to $70 \%$ which means that the vehicle does not generate income for almost one third of the working time because of the rest time. For example, Nagy Horváth [9] studied the implications of adaption of autonomous buses for the city of Eger, Hungry which is a medium sized city with about 50.000 inhabitants based on the following assumptions:

a. Autonomous buses were considered as not requiring inter-job breaks and can be used from the start to the end of the service time.

b. The calculations in this study were made using the software PTV VISUM to create block system under specified conditions.

\section{Results show that:}

c. Assuming the continuous service provided by autonomous buses, only 35 buses are enough to provide the service instead of the 37 bus in the current condition. Additionally, the required number of autonomous buses can be reduced to 32 buses to provide the same service in case of optimizing the bus schedule.

d. In addition to the savings in the required number of buses, autonomous buses provide significant savings in the human resources.

e. Financial analysis show that although the purchasing cost of autonomous buses is much higher than the conventional human driven bus, the operating cost of ABs is much lower than human driven buses as follows:

a. The operating costs of the current system are almost $€$
10200 per day or $€ 3.08$ million annually.

b. The daily operating cost of autonomous buses with the current schedule is $€ 6900$ or $€ 2.08$ million annually.

c. In the case of schedule optimization, the daily operational costs of autonomous buses is $€ 6644$ or $€ 1.9$ million annually.

d. It means that autonomous buses have the potential to reduce the operating costs by almost $30 \%$.

e. Additionally, the financial analysis shows that the bigger vehicle purchase cost will be equalized (breakeven) by operational cost savings in about 5 years so the system will be cheaper than the current system.

Additionally, Dai et al. [10] studies a new operating strategy that can deal with the sudden changes in demand (demand responsive strategy) for one-way loop high frequency bus line with 10 equally spaced stops. What is unique on this study is that it considers mixed fleet of human driven and autonomous buses with different penetration rates: $0 \%, 50 \%$, and $100 \%$ autonomous buses. Additionally, this study considered two demand patterns: high crowdedness and low crowdedness. While the term "dynamic headway" is a common term in transit as transit agencies uses dynamic headways to serve the demand during the peak and offpeak periods, the term "dynamic capacity" was used for the first time in 2020 by Dai et al. [10].

Dai et al. [10] used the following assumptions in their study:

a. The dynamic capacity is obtained by assembling and/or dissembling multiple autonomous minibuses at terminals.

b. Autonomous buses have a capacity of 6 passengers, and the capacity of the human driven bus is 45 passengers.

c. A maximum of 5 autonomous buses can be assembled together.

d. Considering a single line.

e. Autonomous buses can self-adjustment their headway based on the headways of the forward and backward buses by adjusting their travel time.

Results show that:

a. Providing dynamic headway and dynamic capacity have the potential to provide high level of service as it reduces the average passenger waiting time

b. The dynamic scenario (dynamic headway and capacity) reduce the headway deviation. Additionally, this deviation diminishes with the increase the level of penetration of autonomous buses.

c. Autonomous buses increase the bus capacity utilization. Thus, the introduction of autonomous buses will increase the bus efficiency utilization. 


\section{Civil Engineering Research Journal}

In conclusion, automation of buses has many benefits to passengers (reduce the average waiting time) which increase the attractiveness of the transit service. Additionally, agencies will benefit from the introduction of autonomous buses as it will increase the vehicle utilization, attract more people and increase their revenue. Additionally, this solution might increase the VKT slightly because of the increase in the number of required buses. On the other hand, this might not be harmful because of the adaption of electric and autonomous buses. In this scenario, the first mile last mile problem still exists. Thus, the use of a combination of the two scenarios two and three in order to derive the optimal benefits of the automation technology. In this combined scenario, shared autonomous buses will be used as a first mile last mile on demand service to support the public transit system and transit lines will switch gradually from human driven buses to autonomous buses. Additionally, the use of electric buses is a must to increase the economic and social value of transit [1118].

\section{Conclusion}

The introduction of autonomous vehicles is expected to have a significant influence on the entire transportation system. In this paper three scenarios of adaption of autonomous vehicles are discussed. Figure 1 summarizes these scenarios and it is recommended to use a combined scenario to maximize the gain and derive the optimal benefits of the automation technology. In this combined scenario, shared autonomous buses will be used as a first mile last mile on demand service to support the public transit system and transit lines will switch gradually from human driven buses to autonomous buses. Additionally, the use of electric buses is a must to increase the economic and social value of transit. Additionally, it must be mentioned that regulations will play an important rule on the impact of vehicle automation on public transportation. Additionally, the public preference will play a significant rule on which scenario to people will adopt.

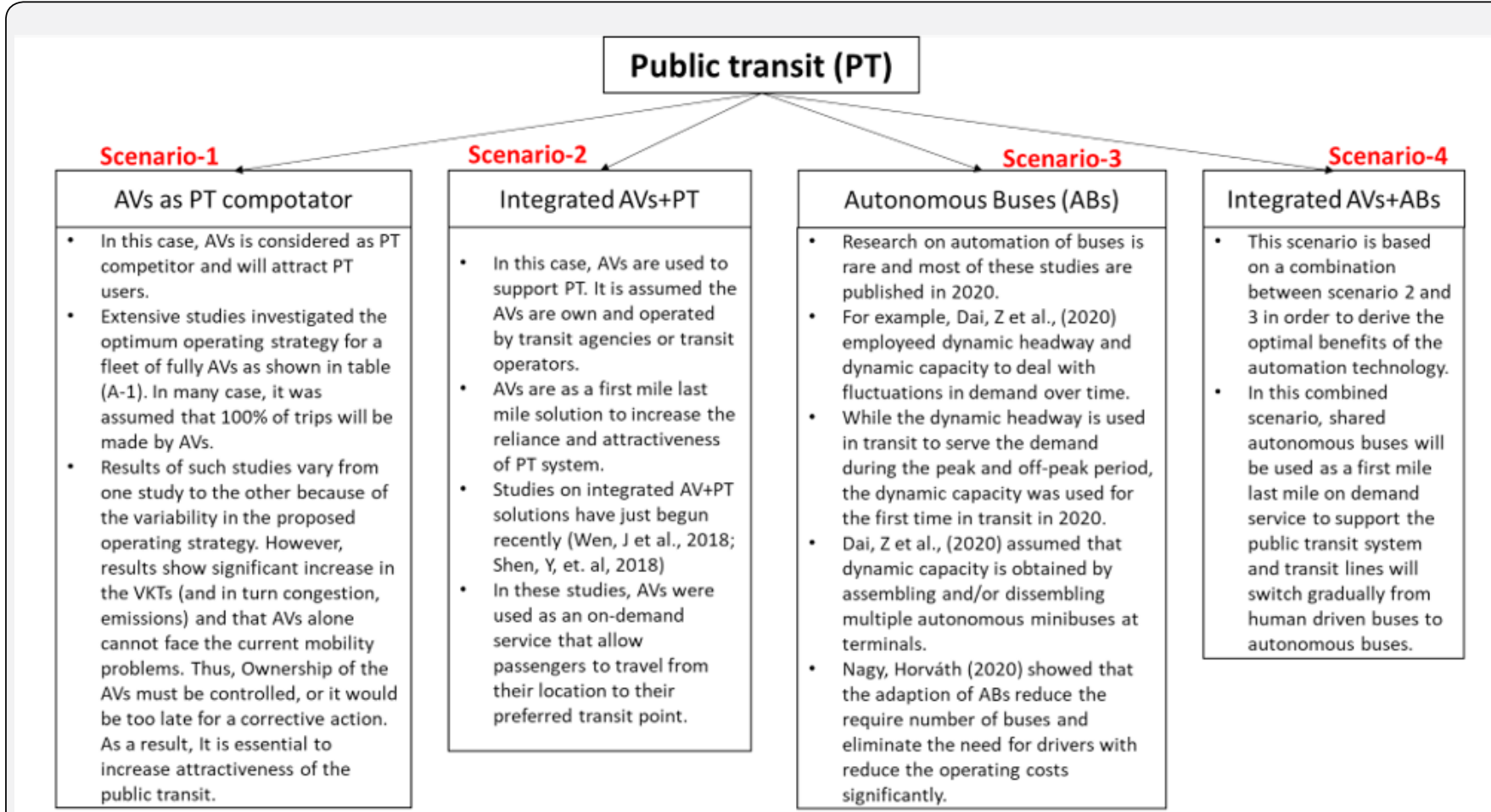

Figure 1: Summarization of the different scenarios of public transit service on the era of autonomous vehicles.

\section{References}

1. Smith BW (2012) Managing autonomous transportation demand. Santa Clara L. Rev. 52(4): 1401.

2. Anderson JM (2014) Autonomous Vehicle Technology: A Guide for Policymakers. Rand Corporation.

3. Gruel W, Stanford JM (2016) Assessing the long-term effects of autonomous vehicles: a speculative approach. Transport. Res. Procedia $13,18-29$.

4. Chen TD, Kockelman KM (2016) Management of a shared autonomous electric vehicle fleet: Implications of pricing schemes. Transp. Res.
Board J. Transp. Res. Board 2572(1): 37-46.

5. Mendes L, Bennàssar M, Chow J (2017) Comparison of light rail streetcar against shared autonomous vehicle fleet for BrooklynQueens connector in New York City. Transp. Res. Record: J. Transp. Res. Board 2650(1): 142-151.

6. Hörl, Sebastian (2016) Simulation of autonomous taxis in a multimodal traffic scenario with dynamic demand.

7. Wen J (2018) Transit-oriented autonomous vehicle operation with integrated demand-supply interaction, Transportation Research Part C: Emerging Technologies 97: 216-234. 


\section{Civil Engineering Research Journal}

8. Shen Y (2018) Integrating shared autonomous vehicle in public transportation system: A supply-side simulation of the first-mile service in Singapore, Transportation Research Part A: Policy and Practice 113: 125-136.

9. Nagy V, Horváth B (2020) The effects of autonomous buses to vehicle scheduling system, Procedia Computer Science 170: 235-240.

10. Dai A (2020) Joint optimization of scheduling and capacity for mixed traffic with autonomous and human-driven buses: A dynamic programming approach, Transportation Research Part C: Emerging Technologies 114: 598-619.

11. Bischoff J, Maciejewski M (2016) Simulation of City-wide Replacement of Private Cars with Autonomous Taxis in Berlin. Procedia Computer Science 83: 237-244

12. Burns L (2012) Transforming Personal Mobility. (The Earth Institute Columbia University) p: 1-42.

13. Fagnant, Daniel, Kockelman Kara (2014) The travel and environmental implication of shared autonomous vehicles using agent-based model scenarios. Transportation Research Part C: Emerging Technologies 40 : $1-13$.

14. (2015) International Transport Forum, Urban Mobility System Upgrade - How shared self-driving cars could change city traffic.

15. Kloostra B, Roorda MJ (2019) Fully autonomous vehicles: analyzing transportation network performance and operating scenarios in the Greater Toronto Area, Canada. Transportation Planning and Technology 42(2): 99-112.

16. Moreno AT (2018) Shared Autonomous Vehicles Effect on VehicleKm Traveled and Average Trip Duration. Journal of Advanced Transportation p: 1-10.

17. Zhang W, Guhathakurta S (2017) Parking Spaces in the Age of Shared Autonomous Vehicles: How Much Parking Will We Need and Where? Transportation Research Record 2651(1): 80-91.

18. Zhang W (2018) The impact of private autonomous vehicles on vehicle ownership and unoccupied VMT generation. Transportation Research Part C: Emerging Technologies 90: 156-165.

\section{Your next submission with Juniper Publishers will reach you the below assets}

- Quality Editorial service

- Swift Peer Review

- Reprints availability

- E-prints Service

- Manuscript Podcast for convenient understanding

- Global attainment for your research

- Manuscript accessibility in different formats

( Pdf, E-pub, Full Text, Audio)

- Unceasing customer service

Track the below URL for one-step submission https://juniperpublishers.com/online-submission.php 